\title{
Adherence to antiretroviral therapy and its associated factors among children at South Wollo Zone Hospitals, Northeast Ethiopia: a cross-sectional study
}

\author{
Getachew Arage ${ }^{1}$, Gizachew Assefa Tessema ${ }^{2 *}$ and Hiwot Kassa ${ }^{3}$
}

\begin{abstract}
Background: Poor adherence to antiretroviral therapy negatively affects the suppression of viral replication. It increases risks of drug resistance, treatment failure, Acquired Immuno Deficiency Syndrome (AIDS)-related morbidity and mortality among children. This study assessed the level of adherence to antiretroviral therapy and its associated factors among children at hospitals in South Wollo Zone, Northeast Ethiopia.

Methods: An institution-based cross-sectional study was conducted among Human Immunodeficiency Virus (HIV)-infected children in April 2013. A total of 464 children who were taking Antiretroviral Therapy (ART) in the hospitals were included. Data were collected using pretested and structured questionnaires using a face-to-face interview method. Descriptive and summary statistics were employed. Bivariate and multiple logistic regressions were computed. Odds ratios and their $95 \%$ confidence intervals were computed to determine the level of significance.
\end{abstract}

Results: Of the 464 study samples, 440 children with their caregivers were included in the final analysis. A total of $78.6 \%$ of the caregivers reported that their children were adherent to antiretroviral therapy in the month prior to the interview. Caregivers' knowledge about antiretroviral treatment $[\mathrm{AOR}=2.72(95 \% \mathrm{Cl}: 1.82,5.39)]$, no current substance use of the caregivers [Adjusted Odds Ratio (AOR) $=2.21$ (95\% Confidence Interval $(\mathrm{Cl})$ : 1.34, 7.13)], proximity to the health care facility $[A O R=2.31(95 \% \mathrm{Cl}: 1.94,4.63)]$, if the child knows HIV-positive status $[A O R=3.47$ $(95 \% \mathrm{Cl}: 2.10,6.81)]$ and caregiver's educational status $[\mathrm{AOR}=0.59(95 \% \mathrm{Cl}: 0.21,0.82)]$ were significantly and independently associated with adherence of children to antiretroviral therapy.

Conclusion: Adherence of antiretroviral therapy in this study was comparable to other studies conducted in developing countries. Caregiver's knowledge about antiretroviral therapy, no current use of substances, close proximity to health facilities, and letting child's know his/her HIV status improves adherence to antiretroviral therapy. Health care providers should educate caregivers about antiretroviral therapy and encourage HIV positive status disclosure to the child.

Keywords: HIV, Adherence, ART, Children, Ethiopia

\footnotetext{
* Correspondence: agizachew@gmail.com

${ }^{2}$ Department of Reproductive Health, Institute of Public Health, University of Gondar, Gondar, Ethiopia

Full list of author information is available at the end of the article
} 


\section{Background}

Globally, of the estimated 34 million people living with HIV in 2011, 3.3 million were children under the age of 15 years. More than $90 \mathrm{cph}$ of these children were residing in sub-Saharan Africa [1]. In 2010, Ethiopia had 1,216,908 people living with HIV of which 79,875 (6.5\%) were children [2]. Antiretroviral Therapy (ART) improves the prognosis of HIV-infected individuals, reduces HIV-related morbidity and mortality, and reduces other opportunistic infections [3-5].

Inadequate adherence increases the risk of drug resistance and treatment failure [6]. Therefore, optimum adherence is essential for sustainable success of ART [7]. Suboptimal adherence among children is common in both developed and developing countries [8]. Taking $\geq 95 \%$ of prescribed doses is recommended for optimal virologic suppression and minimizes the rate of treatment failure $[6,9]$ and decreases risk of virologic failure by more than $50 \%[10]$.

Adherence is a serious challenge for those receiving ART especially children. Factors associated with paediatric ART adherence can be related to caregivers, children themselves, the medication/regimen, socioeconomic, or service delivery issues [11-14].

Unlike adults, young children rely upon their caregivers for their medicines. However, these caregivers may also be ill [14]. In addition, children may not be able to take pills and syrup formulations because of the large size of tablets and poor palatability of syrups $[15,16]$. Furthermore, parents may have a poor understanding of the need to take the medication and they may be unwilling to disclose the child's HIV-positive status to the child or others involved in the care. This may create problems in administering doses while the parent is at work or the child at school (9). HIV develops resistance if the concentration of drugs in the blood is low. Hence, optimal adherence to ART is essential to ensure high level of drugs by taking medication correctly and consistently (10).

As a result, the guideline for paediatric HIV care and treatment in Ethiopia recommends at least two adherence sessions which include caregiver education and counseling before ART initiation. The same guideline also recommends adherence reinforcement at each follow-up visit. Moreover, the limited availability of second-line therapy in resource-limited settings like Ethiopia emphasizes the importance of adherence and preservation of first-line regimens. Therefore, assessment and support of adherence is fundamental to successful antiretroviral therapy and prevention of drug resistance [6]. The findings of this study are particularly helpful to those clinicians who work with paediatric HIV positive patients in third world countries. Hence, this study assessed the level of adherence to ART and associated factors among children at hospitals in South Wollo Zone, Northeast Ethiopia.

\section{Methods}

A facility-based cross-sectional study was conducted in April 2013 at paediatric ART clinics in the three hospitals (Dessie Referral Hospital, Borumeda District Hospital, and Hidar 11 District Hospital) that provide ART services in South Wollo Zone, Northeast Ethiopia. These three hospitals provide services to about 15,000, 1,600 and 2,500 clients living with HIV registered at chronic care follow-up clinics (treated and untreated), respectively. There were 1210 children on chronic HIV care and support follow up at the three hospitals (900 at Dessie, 130 at Borumeda, and 180 at Hidar-11 hospitals). Of these 1210 children, 464 (324 at Dessie, 58 at Borumeda, and 82 at Hidar-11 hospitals) were on ART. Each hospital has its own case managers, adherence supporters, support groups for mothers, and data clerks. Children aged 2 months to 14 years and who were receiving ART for at least one month were included in the study.

The sample size was calculated by considering the assumptions for single population proportion formula: the proportion $(\mathrm{P})=80.9 \%$ of adherence rate in Northwest Ethiopia [17], $\mathrm{Z}=$ standard normal distribution value at $95 \%$ confidence level of $\mathrm{Za} / 2=1.96,5 \%$ of absolute precision, and $10 \%$ non-response rate. Hence, the total sample size was 263 . However, there were 464 children who were taking ART in these hospitals and therefore, all were included.

Pretested and structured questionnaires using face-to-face interviewing with caregivers were used for data collection. The questionnaire was partly adapted from the AIDS Clinical Trial Group (ACTG) adherence follow-up questionnaire [18] and review of similar literature. Pre-testing of the questionnaire was undertaken on 24 caregivers at the Dessie Health Center before the actual data collection. Medical records were reviewed to collect clinical data such as WHO clinical stage and the CD4 count of children. Adherence was measured by the caregivers' report of a one-month recall of missed doses prior to the date of the interview.

Data were collected by five diploma nurses (supervised by three B.Sc nurses). A two days comprehensive training was given to data collectors and supervisors. The questionnaire was first prepared in English and then translated into Amharic (the local language), and back into English to ensure consistency.

The questionnaires were coded and entered into EPI Info version 3.5.3 statistical software and then exported to SPSS windows version 16 for further analysis. Data were summarized and presented using descriptive statistics. Bivariate and multiple logistic regressions were computed to identify the presence and strength of associations. Odds ratios with 95\% CI were computed and variables having p-values less than 0.05 in the multiple logistic regression models were considered significantly associated with the dependent variable (adherence). 
Table 1 Socio-demographic characteristics of the study participants at South Wollo Zone hospitals, Northeast Ethiopia, $2013(n=440)$

Variables $\quad$ Frequency Percentage

\section{Sex of caregiver}

Male

Female

Age of caregiver (in years)

$<20$
$21-30$
$31-40$
$\geq 41$

Ethnicity

Amhara

Tigire

Oromo

Others*

Marital status

Single

Married

Divorced

Widowed

Religion

Muslim

Orthodox Christian

Protestant

Educational status of the caregiver

Can't read and write

Primary school(1-8 grade)

Secondary or above

Substance use of caregivers

User

Non-user

Caregivers income (Ethiopian Birr)

$<=300$

300-999

$\geq 1000$

Occupation

Merchant

House wife

Farmer

Government employee

Other**

Age of children (in years)

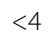

$5-9$

10-14
159

281

36.1

63.9

3.6

26.8

36.8

32.6

143

409

18

10

3

60

240

70

70

245

182

13

223

116

101
Table 1 Socio-demographic characteristics of the study participants at South Wollo Zone hospitals, Northeast Ethiopia, 2013 ( $n=440)$ (Continued)

\begin{tabular}{lcc}
\hline Sex of children & & \\
$\quad$ Male & 210 & 47.7 \\
$\quad$ Female & 230 & 52.3 \\
Children's caregiver & & \\
$\quad$ Biological parents & 343 & 78.0 \\
$\quad$ Other relatives and guardian & 97 & 22.1 \\
WHO Clinical stage & & \\
$\quad$ Stage I & 60 & 13.6 \\
Stage II & 214 & 48.6 \\
$\quad$ Stage III & 161 & 36.6 \\
Stage IV & 5 & 1.1 \\
Baseline CD4 count & & \\
$<200$ & 159 & 36.1 \\
$200-499$ & 224 & 50.9 \\
$\geq 500$ & 57 & 13.0 \\
Current CD4 count & & \\
$<200$ & 6 & 1.4 \\
$200-499$ & 187 & 42.5 \\
$\geq 500$ & 247 & 56.1 \\
\hline$*$ Gurage, Afar * Students, daily laborers. & & \\
& & \\
& &
\end{tabular}

*Gurage, Afar **Students, daily laborers.

\section{Operational definitions}

Adherence to ART in this study was when the children took $\geq 95 \%$ of the prescribed doses in the month prior to the interview. Non-adherence to ART was when the child took less than $95 \%$ of the total doses or missed more than 3 doses in the month prior to the interview. In addition, if a child missed a single dose in the past three and seven days, it was considered non-adherent.

Knowledge about ART was categorised by asking eight questions. Those respondents who scored greater than or equal to the mean for the knowledge questions were considered as knowledgeable, otherwise not.

Attitude about ART was categorised based on five questions using a Likert scale method and the mean scores were computed and then dichotomized into favourable (score $\geq$ mean value) or unfavourable (score $<$ mean value).

\section{Ethical considerations}

Ethical clearance was obtained from the Ethical Review Committee of the College of Medicine and Health Sciences, University of Gondar. An official letter of cooperation was granted to the administrative offices of the three hospitals. Verbal informed consent was obtained from each participant before the start of the interview. Due to the high illiteracy, it was considered impractical to obtain written consent from each study participant. 
Also, assent was secured from those children older than seven years and were aware of their sero-postive status. All interviews were conducted in a private room and confidentiality was insured.

\section{Results}

Socio-demographic and clinical characteristics of the study participants

Of the 464 study participants, 440 children along with their caregivers were included in the analysis, yielding a response rate of $94.8 \%$. With the twenty-four excluded cases, eighteen caregivers did not know the dosing history for the past month and six questionnaires were discarded for being incomplete. Two hundred eighty one (63.9\%) of the caregivers were females. The mean age of the children was 9.4 years $(S D=5.13)$ and $54.8 \%$ of them were between the ages of $10-14$ years. Half $(50.7 \%)$ of the caregivers were unable to read and write. Two hundred and fourteen (48.6\%) of the children were at WHO clinical stage II. One hundred fifty-nine (36.1\%) children had a CD4 count of $<200$ cells $/ \mathrm{mm} 3$ at ART initiation and $56 \%$ had a current CD4 count of $\geq 500$ cells $/ \mathrm{mm}^{3}$ (Table 1).

\section{Knowledge and attitude about ART treatment}

Two-thirds (67\%) of the participants knew about ART before their child was diagnosed. The majority (90\%) of the respondents were knowledgeable and had a favourable attitude towards ART. Three hundred sixty-two (82.3\%) participants reported that taking ART incorrectly would result in resistance to the drugs.

\section{Adherence to ART among children}

Based on the caregivers' report, a total of $78.6 \%$ (95\% CI: $74.8 \%, 82.4 \%)$ children were reported to have an adherence rate of $\geq 95 \%$ in the month prior to interview. The adherence rates to ART among children in the past three and seven days of the interview date were $95.9 \%$ and $89.8 \%$, respectively.

\section{Reasons for non-adherence}

The commonly mentioned reasons for missing these medications were: forgetfulness $(28.4 \%)$, child's refusal to take the drugs (19.3\%); and lack of transportation access to the facilities (19.1\%) (Figure 1).

Factors associated with adherence to ART among children In multiple logistic regression analysis, current substance use of the caregivers, disclosure of HIV status to the child, knowledge of caregivers about ART treatment, distance from the health facility, and educational status of secondary schooling or above of the caregivers, and current CD4 count of 500 or more were significantly and independently associated with adherence.

Children whose caregivers were not currently using substances were 2.2 times more likely to be adherent to ART than those whose caregivers used substances like alcohol, chat and/or cigarettes $[\mathrm{AOR}=2.21$ (95\% CI: 1.94 , 5.39)]. Children who knew their HIV status (disclosed) were 3.6 times more likely to be adherent than their counterparts $[\mathrm{AOR}=3.47(95 \% \mathrm{CI}: 2.10,6.81)$ ].

The present study also showed that children who came from a distance of less than $10 \mathrm{~km}$ were 2.3 times more likely to be adherent to ART compared to those who came from $10 \mathrm{~km}$ or above [AOR $=2.31(95 \% \mathrm{CI}: 1.94,4.63)]$.

If the caregiver was knowledgeable about ART treatment, the child was 2.7 times more likely to be adherent to ART $[\mathrm{AOR}=2.72(95 \% \mathrm{CI}: 1.82,7.13)]$. Those children whose caregivers had secondary or above educational status were $0.41 \%$ less likely to be adherent than those children with caregivers who did not read and write [AOR = 0.59(95\% CI: 0.21, 0.83)]. Those children whose current CD4 count of 500 or greater were 1.89 times more likely to be adherent than those children with CD4 count less than $500[\mathrm{AOR}=1.89(95 \% \mathrm{CI}: 1.34,3.87)]$ (Table 2).

\section{Discussion}

This study assessed the rate of antiretroviral therapy adherence and its associated factors among children at South Wollo Zone Hospitals, Northeast Ethiopia. The level of adherence to ART treatment was found to be

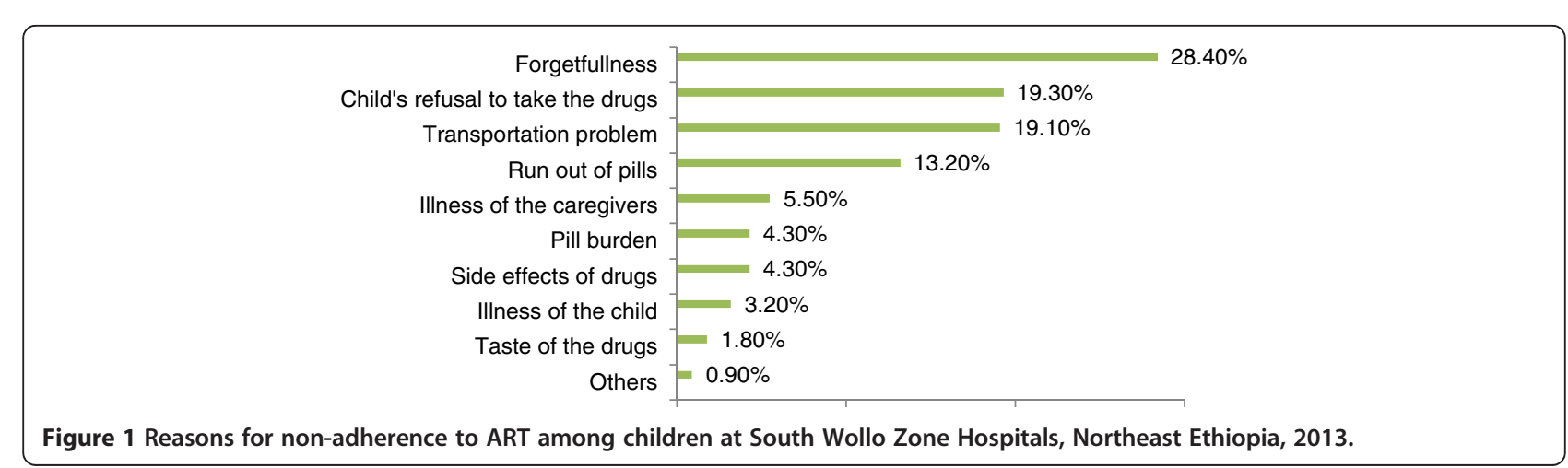


Table 2 Crude and adjusted odds ratios (OR) and 95\% confidence intervals (CI) of determinants adherence to HAART at South Wollo Zone hospitals, Northeast Ethiopia, $2013(n=440)$

\begin{tabular}{|c|c|c|c|}
\hline \multirow[t]{2}{*}{ Variables } & \multicolumn{2}{|c|}{ Adherence status } & \multirow[b]{2}{*}{$\operatorname{COR}(95 \% \mathrm{Cl}$} \\
\hline & Adherent & Non- adherent & \\
\hline \multicolumn{4}{|c|}{ Sex of the caregivers } \\
\hline Male & 119 & 40 & 1 \\
\hline Female & 227 & 54 & $1.4(0.88,2.25)$ \\
\hline \multicolumn{4}{|c|}{ Age of the caregivers } \\
\hline$<30$ & 106 & 28 & 1 \\
\hline $31-40$ & 133 & 29 & $1.29(0.73,4.07$ \\
\hline$\geq 41$ & 102 & 33 & $0.49(0.31,2.51$ \\
\hline
\end{tabular}

Educational status of the caregivers

$\begin{array}{ll}\text { Can't read and write } & 175 \\ \text { Elementary school } & 97 \\ \text { Secondary or above } & 74\end{array}$

Substance use of the caregivers*

Used 29

Caregivers knowledge about ART

$\begin{array}{lr}\text { Knowledgeable } & 320 \\ \text { Non knowledgeable } & 26\end{array}$

Attitude of caregivers towards ART

$\begin{array}{lr}\text { Favourable } & 294 \\ \text { Unfavourable } & 52\end{array}$

Taking medication besides ART

$\begin{array}{lc}\text { Yes } & 26 \\ \text { No } & 320\end{array}$

Distance from the health facility

$$
\begin{array}{ll}
<10 \mathrm{Km} & 246 \\
\geq 10 \mathrm{Km} & 100
\end{array}
$$

Disclosure of HIV status

$\begin{array}{ll}\text { Yes } & 216 \\ \text { No } & 130\end{array}$

CD4 count at the start of treatment

$\begin{array}{lc}<200 & 118 \\ 200-499 & 179 \\ \geq 500 & 49\end{array}$

Getting support

$\begin{array}{lc}\text { Yes } & 73 \\ \text { No } & 273\end{array}$

Current CD4 count

$\begin{array}{ll}<500 & 139 \\ \geq 500 & 207\end{array}$

*p value $<0.05$.

$$
0.16
$$

0.022

0.145
AOR(95\% Cl) P-value

27

15

79

83

273

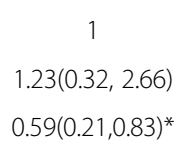

0.033

0.008

$2.07(1.07,4.05)$

$2.71(1.40,5.25)$

0.004

$$
2.21(1.34,5.39)^{*}
$$

$2.72(1.82,7.13)^{*}$

0.030

$0.38(0.28,6.24)$

1

$0.54(0.52,5.37)$

$2.6(1.68,4.22)$

1

$3.9(2.39,6.4)$

0.041

0.029

$3.47(2.10,6.81)^{*}$

0.001

0.003

$2.31(1.94,4.63)^{*}$
1

0.18

$1.3(0.85,2.25)$

2.12(0.93,4.87)

$2.01(1.02,3.98)$

0.03

0.022

1

$2.01(1.27,3.19)$ 
$78.6 \%$ in the past one month caregivers' reports. This finding is comparable to similar studies conducted in Ethiopia (80.9\%) [17], Nigeria (80\%) [19], Togo (80\%) [20], and Vietnam (75.1\%) [21].

This finding is also comparable with a systematic review of paediatric ART adherence studies in middle- and low-income countries (75\%) [22]. Nevertheless, it was lower than studies conducted in the United States (84\%) [22], Jamaica (87.5\%) [23], New Delhi (91.4\%) [24] but higher than studies conducted in Brazil (50.5\%) [25], and Kenya (44.2\%) [26].

In the present study, caregivers' forgetfulness was reported as the major reason $(28.4 \%)$ for missing doses. Studies conducted in Brazil, Kenya, and Nigeria [25-27] supported this finding. This could be due to the caregivers being busy with their daily routines which, in turn, lead the caregivers to easily forget to administer the pills as prescribed. Similar to other studies [28-30], child refusal to take medication (19.3\%) and lack of transport access to reach facilities (19\%) lead them to miss doses.

A number of factors were reported as predictors of adherence among children on ART. In the present study, if the caregiver uses substances then the child was less likely to be adherent to ART. A studies conducted in Vietnam [21], Nepal [30], and South Africa [31] showed similar findings. This might be due to substance use could lead them to forget administration of the drugs. Forgetfulness is one of the reasons for missing doses in children as shown by this study (28.4\%).

The findings also showed that those children who have been disclosed of their HIV status were about four times more likely to be adherent to ART than those who had not been disclosed of their HIV status. This finding is supported in studies conducted at Uganda [32] and Democratic Republic of Congo [16]. This may be seen from two overlapping, yet separate, angles. Firstly, children who knew they are HIV-positive status can be more concerned on their health and could aware that these drugs are helpful. Secondly, nondisclosed children might not understand the rationale behind taking drugs and become resistant to take them as they fail to understand why they take medicine while feeling apparently healthy.

This study also showed that children's adherence to ART is associated with distance from the health facilities which is in line with findings from Ethiopia [28], Nepal [30], and South Africa [31]. This could happen because the clients miss appointments due to difficulties in reaching the treatment centres. Lack of transportation, long traveling distance, and geographical inaccessibilities might be the reasons.

In the present study, caregivers knowledge about ART treatment was associated with the child's adherence to ART. This finding is consistent with that of a study conducted in Addis Ababa [28]. If caregivers do not understand benefits of ART to children, they might be poor motivated to administer drugs timely and regularly.

Unlike other studies [30,33], in this study educational status of caregiver was negatively associated with adherence to ART. Children whose caregivers had secondary and above education were less likely to adhere to ART compared to children whose caregivers were not able to read and write. This could be explained by the idea that these caregivers were more likely employed and thus spend less time with the child to administer the drugs consistently or forget doing so amidst busy days.

In the present study, children whose current CD4 count of 500 or greater were about two times more likely to be adherent than those children with CD4 count less than 500 . It could be surmised that long-term adherence leads to higher CD4 counts i.e. CD4 increases as a result of optimal adherence to ART.

However, the present study does have some inherent limitations. Due to financial constraints, adherence was assessed through a self-reporting adherence questionnaire instead of other more objective tools. Caregivers' reports might lead to overestimated adherence. Though efforts made during data collection to minimize the social desirability and recall biases, these may not be eliminated. This study did not assess the adherence related to the correct timing for ART drug administration. The cross-sectional nature of the study which used a snapshot of adherence at one point in time may hinder the accuracy of adherence.

\section{Conclusion}

Adherence to ART in the study area was comparable to other studies conducted in developing countries. The caregiver's knowledge about ART, non-usage of substances, proximity to health facilities, and disclosing the child's HIV status were associated with adherence to ART. Health care providers should educate caregivers about ART and avoidance of substance use. Further attempts are also needed to encourage caregivers to disclose the HIV status to the children.

\section{Competing interests}

The authors declare that they have no competing interests.

\section{Authors' contributions}

GA wrote the proposal, participated in data collection, analyzed the data and drafted the paper. GAT and HK approved the proposal with revisions, participated in data analysis and revised subsequent drafts of the paper. All authors read and approved the final manuscript.

\section{Acknowledgement}

We are very grateful to University of Gondar for the approval of the ethical clearance and Amhara regional Health Bureau for financial support. We would also like to thank all children and caregivers who participated in this study for their commitment in responding to our interviews. Our gratitude also goes to supervisors, the data collectors and the staffs at the ART clinics of the three hospitals. 


\section{Author details}

${ }^{1}$ Department of Nursing, College of Health Sciences, Debre Tabor University, Debre Tabor, Ethiopia. ${ }^{2}$ Department of Reproductive Health, Institute of Public Health, University of Gondar, Gondar, Ethiopia. ${ }^{3}$ Department of Nursing, College of Medicine and Health Sciences, University of Gondar, Gondar, Ethiopia.

Received: 7 July 2013 Accepted: 2 April 2014

Published: 15 April 2014

\section{References}

1. UNAIDS: "Global report: UNAIDS report on the global AIDS epidemic 2012," Tech. Rep., United Nations Programme on HIV/AIDS, Geneva, Switzerland, 2012.

2. Federal Ministry of Health, Ethiopia: National Comprehensive PMTCT/NMCH Training Package. Reference Manual. Addis Ababa, Ethiopia. Ethiopia: Federal Ministry of Health; 2011.

3. Memirie ST: Clinical outcome of children on HAART at police referral hospital, Addis Ababa, Ethiopia. Ethiop Med J 2009, 47(2):159-164.

4. Mea K: Mortality and clinical outcomes in HIV-infected children on antiretroviral therapy in Malawi, Lesotho, and Swaziland. Pediatrics 2012, 130(3):591-599.

5. Vreeman RC, Nyandiko WM, Ayaya SO, Walumbe EG, Marrero DG, Inui TS: The perceived impact of disclosure of pediatric HIV status on pediatric antiretroviral therapy adherence, child well-being, and social relationships in a resource-limited setting. AIDS Patient Care STDS 2010, 24(10):639-649.

6. Federal Ministry of Health, Ethiopia: Ministry of Health Ethiopia \& Federal HIVI AIDS Prevention and Control Office: Guidelines for paediatric HIV/AIDS care and treatment in Ethiopia. Addis Ababa, Ethiopia: Federal HIV/AIDS Prevention and Control Office, Federal Ministry of Health; July 2008.

7. Starace F, Massa A, Amico KR, Fisher JD: Adherence to antiretroviral therapy: an empirical test of the information-motivation-behavioral skills model. Health Psychol 2006, 25(2):153-162.

8. Nischal KC, Khopkar U, Saple DG: Improving adherence to antiretroviral therapy. Indian J Dermatol Venereol Leprol 2005, 71(5):316-320.

9. Osterberg L, Blaschke T: Adherence to medication. N Engl J Med 2005, 353:487-497.

10. Shah CA: Adherence to High Activity Antiretroviral Therapy (HAART) in pediatric patients infected with HIV: Issues and interventions. Indian J Pediatr 2007, 74(1):55-60.

11. Haberer J, Mellins C: Pediatric adherence to HIV antiretroviral therapy. Current HIV/AIDS Rep 2009, 6(4):194-200.

12. Buchanan AL, Montepiedra G, Sirois PA, Kammerer B, Garvie PA, Storm DS, Nichols SL: Barriers to medication adherence in HIV-infected children and youth based on self- and caregiver report. Pediatrics 2012, 129(5):1244-1251.

13. Martin S, Elliott-DeSorbo DK, Wolters PL, Toledo-Tamula MA, Roby G, Zeichner S, Wood LV: Patient, caregiver and regimen characteristics associated with adherence to highly active antiretroviral therapy among HIV-infected children and adolescents. Pediatr Infect Dis J 2007, 26(1):61-67.

14. Prendergast A, Tudor-Williams G, Jeena P, Burchett S, Goulder P: International perspectives, progress, and future challenges of paediatric HIV infection. Lancet 2007, 370(9581):68-80.

15. Lodha R, Manglani M: Antiretroviral therapy in children: recent advances. Indian J Paediatr 2012, 79(12):1625-1633.

16. Fetzer BC, Mupenda B, Lusiama J, Kitetele F, Golin C, Behets F: Barriers to and facilitators of adherence to pediatric antiretroviral therapy in a sub-Saharan setting: insights from a qualitative study. AIDS Patient Care STDS 2011, 25(10):611-621.

17. Azmeraw D, Wasie B: Factors associated with adherence to highly active antiretroviral therapy among children in two referral hospitals, northwest Ethiopia. Ethiop Med J 2012, 50(2):115-124.

18. ACTG Adherence Baseline and Follow up Questionnaires. [http://www ghdonline.org/uploads/ACTG_Adherence_Baseline_Questionnaire.pdf].

19. Mukhtar-Yola M, Adeleke S, Gwarzo D, Ladan ZF: Preliminary inevstigation of adherence to antiretroviral therapy among children in Aminu Kano Teaching Hospital, Nigeria. Afr J AIDS Res 2006, 5(2):141-144.

20. Polisset J, Ametonou F, Arrive E, Aho A, Perez F: Correlates of adherence to antiretroviral therapy in HIV-infected children in Lome, Togo, West Africa. AIDS Behav 2009, 13(1):23-32.

21. HM DO, Dunne MP, Kato M, Pham CV, Nguyen KV: Factors associated with suboptimal adherenceto antiretroviral therapy in Viet Nam:a cross-sectional study using audio computer-assisted self-interview (ACASI). BMC Infect Dis 2013, 13:154.

22. Vreeman RC, Wiehe SE, Pearce EC, Nyandiko WM: A systematic review of pediatric adherence to antiretroviral therapy in low- and middle-income countries. Pediatr Infect Dis J 2008, 27(8):686-691.

23. White YRG, Pierre RB, Steel-Duncan J, Palmer P, Evans-Gilbert T, Moore J, Rodriguez B, Christie CDC, Kingston Paediatric and Perinatal HIV/AIDS Study Group: Adherence to antiretroviral drug therapy in children with HIV/ AIDS in Jamaica. West Indian Med J 2008, 57(3):231.

24. Bhattacharya M, Dubey AP: Adherence to antiretroviral therapy and its correlates among HIV-infected children at an HIV clinic in New Delhi. Ann Trop Paediatr 2011, 31(4):331-337.

25. Wachholz NIR, Ferreira J: Adherence to antiretroviral therapy in children: a study of prevalence and associated factors. Cad Saude Publica 2007, 23(3):424-434.

26. Langat NT, Odero W, Gatongi P: Antiretroviral drug adherence by HIV infected children attending Kericho District Hospital, Kenya. East Afr J Public Health 2012, 9(3):101-104.

27. Ugwu R, Eneh A: Factors influencing adherence to paediatric antiretroviral therapy in Portharcourt, South- South Nigeria. Pan Afr Med J 2013, 16:30.

28. Biadgilign S, Deribew A, Amberbir A, Deribe K: Barriers and facilitators to antiretroviral medication adherence among HIV-infected paediatric patients in Ethiopia: A qualitative study. SAHARA J 2009, 6(4):148-154.

29. Biressaw S, Erku W, Abebe M, Workeabeba Abebe W,MB: Adherence to Antiretroviral Therapy and associated factors among HIV infected children in Ethiopia: unannounced home-based pill count versus caregivers' report. BMC Pediatr 2013, 13:132.

30. Wasti SP, Simkhada P, Randall J, Freeman JV, VanTeijlingen E: Factors influencing adherence to antiretroviral treatment in Nepal: a mixed methods study. PLOS ONE 2012, 7(5):35547.

31. Jaspan HB, Mueller AD, Myer L, Bekker LG, Orrell C: Effect of caregivers' depression and alcohol use on child antiretroviral adherence in South Africa. AIDS Patient Care STDS 2011, 25(10):595-600.

32. Nabukeera-Barungi N, Kalyesubula I, Kekitiinwa A, Byakika-Tusiime J, Musoke P. Adherence to antiretroviral therapy in children attending Mulago Hospital, Kampala. Ann Trop Paediatr 2007, 27(2):123-131.

33. Kleeberger CA, Phair JP, Strathdee SA, Detels R, Kingsley L, Jacobson LP: Determinants of heterogeneous adherence to HIV-antiretroviral therapies in the multicenter AIDS cohort study. J Acquir Immune Defic Syndr 2001, 26:82-92.

doi:10.1186/1471-2458-14-365

Cite this article as: Arage et al:: Adherence to antiretroviral therapy and its associated factors among children at South Wollo Zone Hospitals, Northeast Ethiopia: a cross-sectional study. BMC Public Health 2014 14:365.

\section{Submit your next manuscript to BioMed Central and take full advantage of:}

- Convenient online submission

- Thorough peer review

- No space constraints or color figure charges

- Immediate publication on acceptance

- Inclusion in PubMed, CAS, Scopus and Google Scholar

- Research which is freely available for redistribution 